\title{
ORBITAL VARICOCELE*
}

BY

\author{
B. S. JAIN AND K. N. SRIVASTAVA \\ Willingdon Hospital, New Delhi
}

ORBITAL varicocele (venous angioma) is a rare condition which produces the clinical picture of intermittent exophthalmos, brought about by obstruction of the venous drainage from the head, such as changes in posture, coughing, sneezing, vomiting, straining, tying a collar around the neck, and forcibly blowing against the closed mouth and nostrils.

\section{Case Report}

A woman aged 65 years came to the hospital in April, 1963, with the complaint of pain and protrusion of the right eye on lying down, which made it difficult for her to sleep.

This distressing exophthalmos also occurred on coughing, sneezing, vomiting, stooping, and lifting. She had first noticed it some 4 years before, until which time the eye had been perfectly normal except for occasional irritation. She could not relate the onset to any particular event, and gave no history of trauma. Nothing significant could be discovered in her past, personal and family history.

Examination.-When the patient was sitting on a stool, the right eye looked more prominent than the left (Fig. 1). To demonstrate the protrusion, she lay on her right side with head flexed on the chest, and the exophthalmos markedly increased, reaching its maximum in about 10 minutes (Fig. 2). The exophthalmos was reducible but non-pulsatile. No bruit could be heard on either the closed eyelid or the temple.

When she sat up again, the exophthalmos receded, and the eye returned to its original state.

It was confirmed that the exophthalmos also occurred on coughing, sneezing, stooping, straining, and on forced expiration against the closed mouth and nose (Fig. 3).

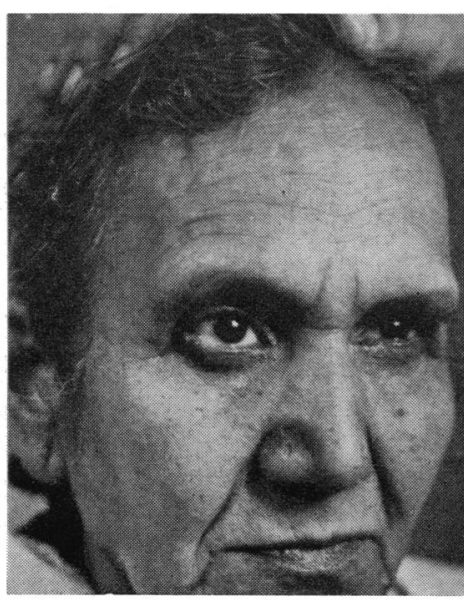

FIG. 1.-Right eye more prominent than the left.

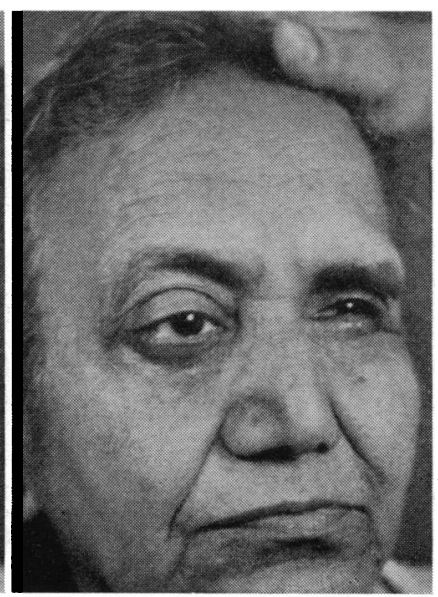

FIG.2.-Exophthalmos increased on lying down.

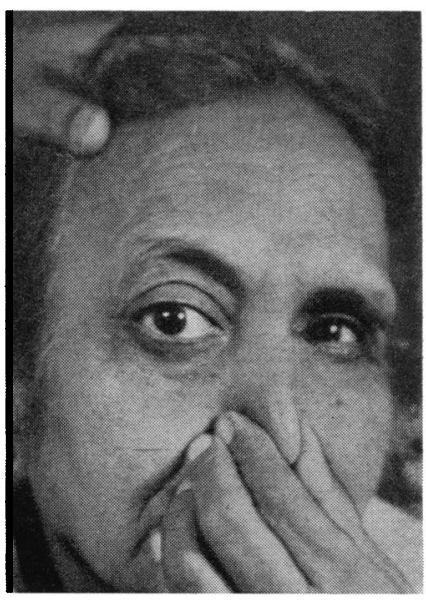

Fig. 3.-Exophthalmos increased on forcible expiration against the closed mouth and nostrils. 
A collar was tied around the neck to obstruct the venous drainage, and this also caused exophthalmos.

The visual acuity was $6 / 24, J_{1}$ in each eye with correction.

Apart from moderately advanced lenticular changes in both eyes, there was no abnormality in the iris, pupil, fundi, visual fields, pupillary reactions, ocular tension, and ocular movements. The conjunctiva was normal in colour and there was no chemosis.

One would expect an increase in the visual field when the eye protrudes forward, but this phenomenon could not be demonstrated.

Diagnosis.-The clinical diagnosis of orbital varicocele in a case with such a typical symptomatology was not difficult. $X$ rays of the right orbit showed multiple round densities indicating calcified phleboliths in a venous angioma (Fig. 4). There was no difference in the size of the orbital fissures.

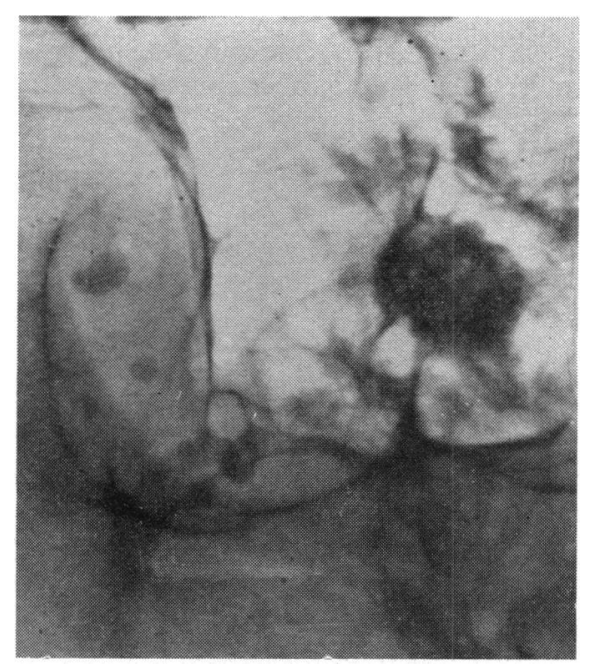

FIG. 4. $-X$ ray of the orbit, showing multiple round densities indicating calcified phleboliths.

\section{Comment}

We have seen two cases of orbital varicocele, which is a very uncommon condition. Curiously enough, both patients were women and in both the right eye was affected, although in the cases reported in the literature the left side was most often involved. A small jugular foramen or a smaller superior orbital fissure on the affected side has been suggested as a causative factor. The straighter course of the cephalic veins to the superior vena cava on the right side could be a factor in the aetiology in patients with a local weakness of the vessel wall in the orbit.

I should like to thank Dr. Sarin for the radiological examination of the case and Shri Amolak Singh for the photography. 